\title{
Possible therapeutic use of loperamide for symptoms of lactose intolerance
}

\author{
Andrew Szilagyi MD FRCPC ${ }^{1}$, Alick Torchinsky MD FCSHP ${ }^{2}$, Antoinnette Calacone BSc CCRA ${ }^{3}$
}

A Szilagyi, A Torchinsky, A Colacone. Possible therapeutic uses of loperamide for symptoms of lactose intolerance. Can J Gastroenterol 2000;14(7):581-587.

OBJECTIVES: To examine a potential practical therapeutic use of loperamide (Lo) to decrease the symptoms of lactose intolerance.

SUBJECTS AND METHODS: Nineteen (eight men, 11 women) healthy lactose maldigesters (18 of 19 with symptoms) underwent a $25 \mathrm{~g}$ lactose challenge on five separate days. Breath hydrogen was measured, areas under the curve (AUC) were calculated for $4 \mathrm{~h}$, and 4 and $12 \mathrm{~h}$ symptom scores were recorded. After establishing baseline measurements, test doses of $4 \mathrm{mg}, 8 \mathrm{mg}$ and $12 \mathrm{mg}$ Lo were randomly administered without placebo in a double-blind manner. As well, each subject received seven lactase tablets, in a random, unblinded manner.

RESULTS: The median AUC and mean oral cecal transit time followed dose response expectations; however, only lactase treatment achieved significance. Nevertheless, $8 \mathrm{mg}$ Lo significantly improved symptom scores, which were statistically indistinguishable from those of lactase. Four subjects complained of delayed constipation and cramps with various doses of Lo.

CONCLUSIONS: Lo monotherapy for lactose intolerance is not economical and may have some side effects. However, Lo may be studied further as an adjunctive treatment of lactose intolerance in an effort to reduce the need for complete lactose digestion. Such a manoeuvre may allow rapid colonic adaptation, which in turn may be beneficial for prophylaxis for a number of colonic diseases.

Key Words: Lactase; Lactose intolerance; Loperamide

\section{Possibles indications thérapeutiques du lopéramide pour le traitement symptomatique de l'intolérance au lactose}

OBJECTIFS : Examiner si d'un point de vue pratique, il est possible d'utiliser le lopéramide pour diminuer les symptômes de l'intolérance au lactose.

SUJETS ET MÉTHODES : Dix neuf sujets (huit hommes, 11 femmes) sains mais ne pouvant digérer le lactose (18 sujets symptomatiques sur 19) ont subi un test de provocation avec $25 \mathrm{~g}$ de lactose pendant 5 jours distincts. Nous avons mesuré l'hydrogène expiré, calculé les aires sous la courbe (ASC) pendant 4 heures, et consigné les scores relatifs aux symptômes survenus après 4 et $12 \mathrm{~h}$. Après avoir défini des mesures de référence, nous avons administré des doses d'essai de lopéramide de $4 \mathrm{mg}$, $8 \mathrm{mg}$ et $12 \mathrm{mg}$, au hasard et sans placebo et à double insu. De même, chacun des sujets a reçu sept comprimés de lactase, au hasard et à simple insu. RÉSULTATS : L'ASC médiane et le temps moyen du transit oral-caecal suivaient les effets-doses prévus ; cependant, les résultats n'étaient significatifs que pour le traitement avec la lactase. Néanmoins, $8 \mathrm{mg}$ de lopéramide amélioraient nettement les scores sur les symptômes, ne permettant pas d'un point de vue statistique de les distinguer de ceux obtenus avec la lactase. Quatre sujets se sont plaints de constipation retardée et de crampes après avoir reçu les différentes doses de lopéramide. CONCLUSIONS : Le lopéramide administré en monothérapie contre l'intolérance au lactose n'est pas économique et pourrait même avoir certains effets secondaires. Cependant, cet agent mérite d'être étudié plus longuement comme traitement d'appoint à l'intolérance au lactose visant à réduire le besoin d'une digestion complète du lactose. Cette manœuvre pourrait permettre une rapide adaptation colique, qui à son tour s'avérerait bénéfique en prophylaxie d'un certain nombre de maladies coliques.

\begin{abstract}
A dult onset lactase insufficiency is one of the most common genetic traits, affecting perhaps two-thirds to three-quarters of the population. There are definite ethnic variations in lactose maldigestion (1), and population shifts
\end{abstract}

to dairy-consuming regions can result in gastrointestinal symptoms as a result of increased lactose consumption. While such potential symptoms as gas, bloat and cramps with or without diarrhea are undesirable, there are poten-

${ }^{1}$ Division of Gastroenterology, ${ }^{2}$ Department of Medicine, ${ }^{3}$ Department of Emergency Medicine, McGill University, Montreal, Quebec

Correspondence: Dr A Szilagyi, 6000 Côte des Neiges \#100, Montreal, Quebec H3S 128. Telephone 514-739-7370, fax 514-340-8282

Received for publication March 9, 1999. Accepted September 13, 1999 
tially important benefits of continued dairy consumption. These benefits include consumption of calories and calcium, which are important in the prevention of osteoporosis (2) and possibly the prevention of colon cancer (3).

Lately, however, information has been presented that contends that lactose and other disaccharides may be protective against a number of colonic diseases. Methods of protection include reduction of some colonic bacterial pathogens, colorectal cancer and inflammatory bowel diseases. The mechanisms postulated possibly involve alterations in colonic $\mathrm{pH}$, metabolism and colonic bacterial ecology (4-6).

Because of these potential benefits, the concept that colonic bacterial adaptation is the preferred management for lactose-derived symptoms was offered as an alternative to withdrawing or predigesting lactose. In this case, regular doses of lactose-containing food are offered. With time (as short as eight days), colonic bacterial metabolism and ecology are altered, and symptoms of lactose intolerance improve, albeit not completely $(7,8)$.

Another method to reduce symptoms initially and allow colonic adaptation may be by artificially prolonging oral cecal transit. The concept that altered small intestinal transit influences symptoms is derived from the studies of Read et al (9) and Ladas et al (10). These two groups showed that symptoms and hydrogen production by bacteria are related to the rate and magnitude of exhaled breath hydrogen after a carbohydrate load $(9,10)$. Improved lactose tolerance has also been observed in previously intolerant women during pregnancy (11). During their third trimester, both a prolonged oral cecal transit time (OCTT) and an increased dairy consumption $(11,12)$ were observed.

To determine whether prolonged OCTT alone could contribute to improved symptoms in pregnancy, we carried out an open-labelled study in men using the well known drug loperamide (Lo). We found significant symptomatic improvement using $12 \mathrm{mg}$ Lo with a $50 \mathrm{~g}$ lactose challenge in lactose intolerant men (13).

The findings in this latter study and the shift in concepts about lactose maldigestion, coupled with the finding of incomplete digestion with several lactase products (14), prompted us to carry out a further trial of Lo as a potential therapeutic agent for lactose intolerance.

Furthermore, results from such a study may be therapeutically applicable to other carbohydrate intolerances in which no specific therapy other than dietary restriction exists.

In this study, a more physiological lactose challenge is administered and the use of lower doses of Lo is explored.

\section{SUBJECTS AND METHODS}

Subjects: Nineteen healthy, multiethnic, lactose maldigesting, average weight subjects were recruited to undergo hydrogen breath tests. There was no history of current or chronic disease. History of lactose intolerance a priori was not a requirement for entry, although subjects were asked about symptoms with milk ingestion. However, only six subjects actually noted dairy intolerance, while one claimed to have severe intolerance. The rest either avoided dairy products or were tolerant under normal daily conditions. No subject had received antibiotics within one month of the study. All subjects gave written informed consent for blood and breath tests. Parental consent was also obtained for one subject who was 17 years old. The study was approved by the Ethics Review Board of the Sir Mortimer B Davis Jewish General Hospital, Montreal, Quebec. All trial runs were carried out at one institution over a 14-month period.

Experimental design: Usual diets were not modified during the studies. On evenings before breath hydrogen testing, subjects were asked to refrain from eating a high carbohydrate meal. Studies were started the next morning between 08:30 and 09:00 after a 12 to $14 \mathrm{~h}$ fast. At entry into the study, blood was drawn for a complete blood count and biochemical profile, and to assess thyroid-stimulating hormone levels. These were analyzed by standard commercial kits, and with the exception of one patient with thalassemia minor, they were all normal. Subjects refrained from eating, chewing gum, smoking or strenuous exercise. Subjects were allowed to drink water during the $4 \mathrm{~h}$ study. Both men $(\mathrm{n}=8)$ and women $(n=11)$ were recruited - independent of menstrual cycles in the latter case. The nature of the study was explained to subjects, but care was taken to avoid disclosing expectations about Lo or lactase. The initial breath hydrogen study established a baseline for quantity of exhaled hydrogen and symptom score (SS) after a challenge with 25 $\mathrm{g}$ lactose dissolved in $240 \mathrm{~mL}$ water. After establishing lactose maldigestion and intolerance, subjects continued to undergo, in random order, four other such runs. These were preceded $30 \mathrm{~min}$ by three doses of Lo (Imodium, McNiel Consumer Products Co, Guelph, Ontario) and one was preceded immediately by ingestion and chewing of seven tablets of lactase (Lactaid, McNeil Consumer Products Co, Guelph, Ontario). One Lactaid tablet contains 3300 lactase units. The dosing of Lo $(4,8,12 \mathrm{mg})$ was conducted in a doubleblind, random fashion by the Department of Pharmacy. A suspension was made by mixing crushed Lo with adraganthe (2 mg), $2 \mathrm{~mL}$ of glycerin and one drop of peppermint flavour $(0.2 \mathrm{~mL})$, bringing the volume to $10 \mathrm{~mL}$ with water. Lactase tablets were given at a dose considered to give maximum beneficial effect (seven tablets). Study intervals were usually separated by a median of seven days, with a range of two to 35 days to avoid possible bacterial adaptation.

Breath hydrogen tests and SS: End expiratory alveolar hydrogen was measured after the $25 \mathrm{~g}$ lactose was dissolved in $240 \mathrm{~mL}$ of water. All breath hydrogen measurements were carried out with a hand held electrochemical hydrogen analyzer (EC 60 Vitalograph Hydrogen monitor Bedfont, USA). This model uses a sealed electrochemical sensor that can detect hydrogen in parts per million (ppm) (volume/volume) in the range of 0 to $2000 \mathrm{ppm}$. The validity of the electrochemical sensors for breath hydrogen measurements has been previously established by comparison with gas chromatography $(15,16)$. The ' 0 ' baseline was adjusted as needed on each run.

Breath hydrogen was measured $10 \mathrm{~min}$ before lactose 


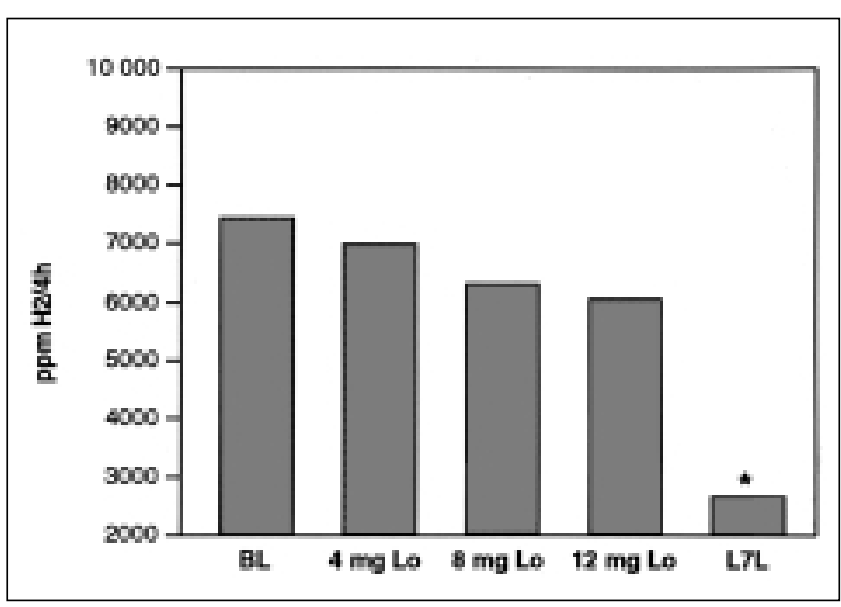

Figure 1) The median area under the curve (AUC) of breath hydrogen measurements ( $\mathrm{ppm} \mathrm{H}_{2} / 4 \mathrm{~h}$ ) with baseline (BL) and interventions. The AUC for seven lactase tablets (L7L) (asterisk) compared with baseline achieved statistical significance $(P<0.05)$. Lo Loperamide

challenge, at time 0 , then at 15 min intervals until the first rise $10 \mathrm{ppm}$ above baseline was achieved (17). After the first positive rise, measurements were read every half hour for $4 \mathrm{~h}$. Each time interval data recording consisted of the average of three breaths. The baseline was defined as the average recording of the first three time intervals.

Breath hydrogen readings were compared by subtracting baseline measurements from readings at each time interval. The area under the curve (AUC) was calculated by summing the trapezoids between each 30 min interval up to $4 \mathrm{~h}$. This method was found to be the most precise for comparisons and for quantifying carbohydrate malabsorption (18).

The OCTT was calculated by a slight modification of an established method using lactulose as follows:

$$
\text { OCTT } \quad \text { (to tp) } 15 \mathrm{~min}
$$

where $\mathrm{t}$ is the time interval from time 0 minus the time at which hydrogen concentrations rise $10 \mathrm{ppm}$ above baseline $\left(t_{p}\right)(19)$.

The SS was recorded for four principal symptoms - gas (flatus), bloat, cramps and diarrhea - at each $30 \mathrm{~min}$ interval (symptoms included any in the preceding interval) up to $4 \mathrm{~h}$ and then at $60 \mathrm{~min}$ intervals (by each subject) for up to $12 \mathrm{~h}$ (or until the patient fell asleep at home). For each symptom, a quality scale from 0 to 3 was established. In this scale, $0=$ no symptoms, $1=$ awareness of symptoms or one loose bowel movement, 2 = definite discomfort or two loose bowel movements, and $3=$ intolerable symptoms or three or more loose bowel movements. Any additional symptoms observed by subjects were noted. Symptoms during the $12 \mathrm{~h}$ poststudy period were recorded by subjects on a prepared 'home score sheet', which was returned usually within 48 to $72 \mathrm{~h}$.

Statistical analysis: A database for each subject was established using Statsview statistical package (Abacus Concepts, USA). A Wilcoxon rank sum test was used to compare nonparametric data. A ${ }^{2}$ test was used where appropriate. Correlations between variables were analyzed by using the

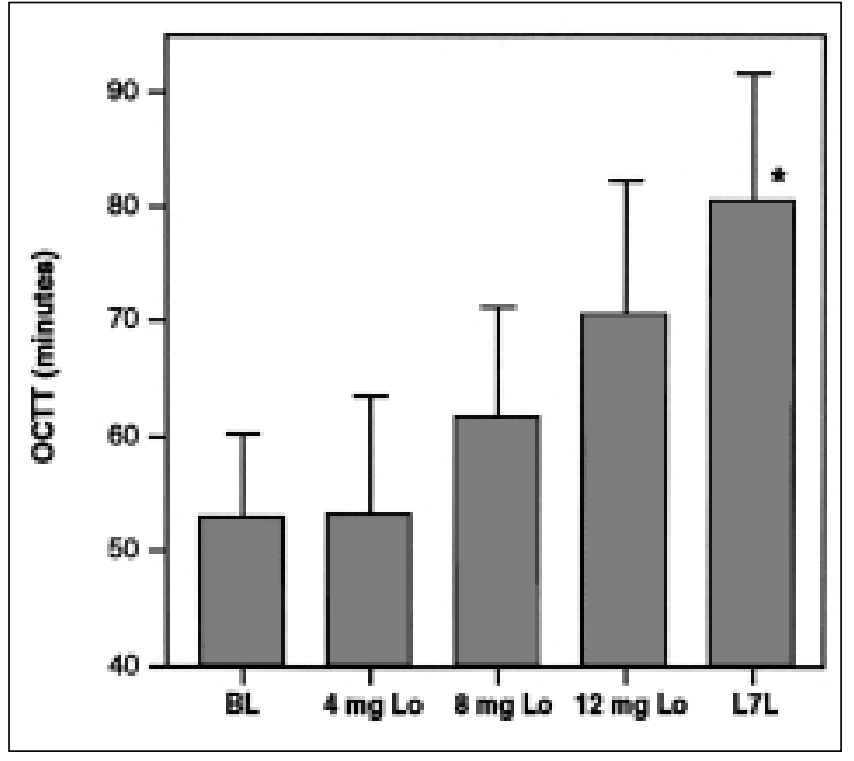

Figure 2) The oral cecal transit time (OCTT minutes) derived following a $25 \mathrm{mg}$ lactose challenge with each intervention $(n=19)$. Only the OCTT (asterisk) after seven lactase tablets (L7L) achieved statistical significance $(P<0.05)$. BL Baseline; Lo Loperamide

Spearman rank correlation coefficient. Medians, means and standard error of the means (SEM) are given. A two-tailed alpha level of 0.05 was accepted to indicate significance. A beta level of $80 \%$ was calculated using the differences in AUC hydrogen found in a previous study. It was estimated that 20 subjects were adequate for statistical power (13).

\section{RESULTS}

The 19 subjects comprised 11 women and eight men. The mean age of the group was $34.9 \pm 2.61$ years (range 17 to 59 years). The ethnic distribution was as follows: nine Asians, three African Americans, three Jews, three Southern Europeans and one French-Canadian. The median AUC for hydrogen $\mathrm{ppm} / 4 \mathrm{~h}$ is depicted in Figure 1. Although a dose response to increasing Lo doses is apparent when the median values are examined, a statistically significant reduction in AUC was achieved only with lactase (seven lactase tablets [L7L]) $(\mathrm{P}=0.0004)$. A trend was noted with $8 \mathrm{mg}$ Lo $(\mathrm{P}=0.099)$. Similarly, there was an apparent dose response to increasing doses of Lo with respect to OCTT (Figure 2). However, only L7L achieved a significant prolongation of $\operatorname{OCTT}(\mathrm{P}=0.01)$. This prolongation in transit time is also affected by an unknown quantity of digested lactose, which reduces osmotic forces of the remaining disaccharide.

Of the 19 subjects tested, 17 were symptomatic throughout the $16 \mathrm{~h}$ of recording (total SS), one was symptomatic only during the initial $4 \mathrm{~h}$ and one never had symptoms. Compared with baseline SS, SS were reduced in 14 subjects with L7L, 10 with $4 \mathrm{mg}$ Lo, 12 with $8 \mathrm{mg}$ Lo and 10 with $12 \mathrm{mg}$ Lo. SS increased in four subjects with L7L, seven with $4 \mathrm{mg} \mathrm{Lo}$, six with $8 \mathrm{mg}$ Lo and eight with $12 \mathrm{mg}$ Lo. One subject remained at the same symptom score with $4 \mathrm{mg}$ Lo. None of these differences was statistically significant (Figure 3). 


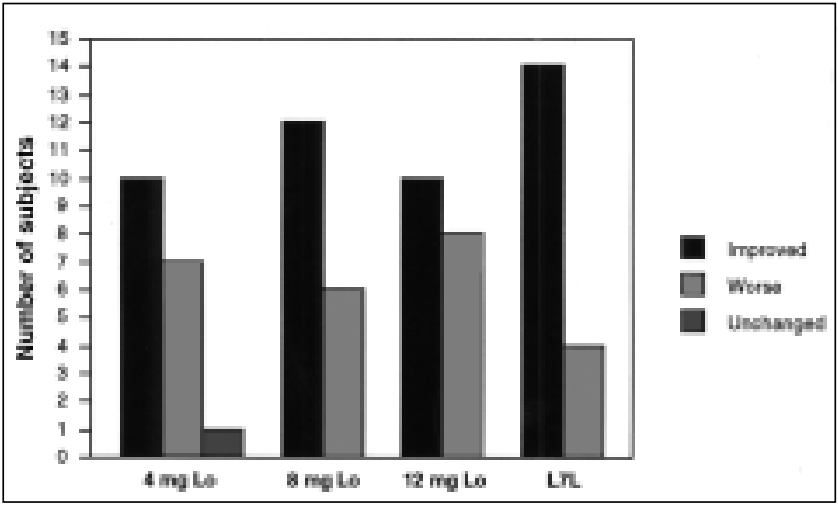

Figure 3) The number of symptomatic subjects at baseline $(n=18)$ who improved, worsened or achieved the same symptom score for each intervention. None of the differences was statistically significance. Lo Loperamide; $L 7 L$ Seven lactase tablets.

TABLE 1

Symptom scores (SS) (mean \pm SEM) $(n=18)$ at baseline $(B L)$ and for each intervention with increasing doses of loperamide (Lo) 4 to $12 \mathrm{mg}$ or seven tablets of lactase (L7L) for the $16 \mathrm{~h}$ total symptom score (TSS), and $4 \mathrm{~h}$ and $12 \mathrm{~h}$ SS scores

\begin{tabular}{lcrccc}
\hline & BL & 4 mg Lo & 8 $\mathbf{~ m g ~ L o ~}$ & $\mathbf{1 2} \mathbf{~ m g ~ L o}$ & \multicolumn{1}{c}{ L7L } \\
\hline TSS & $24.1 \pm 3.2$ & $19.5 \pm 3.8$ & $15.2 \pm 2.7^{*}$ & $21.3 \pm 3.8$ & $14.1 \pm 3.8^{*}$ \\
4 h SS & $12.9 \pm 1.8$ & $9.1 \pm 1.8$ & $7.3 \pm 1.4^{*}$ & $11.2 \pm 2.2$ & $7 \pm 1.8^{*}$ \\
12 h SS & $11.7 \pm 2.8$ & $10.2 \pm 3.3$ & $7.6 \pm 1.6$ & $11.2 \pm 2.7$ & $7.8 \pm 2.6$ \\
\hline
\end{tabular}

Maximum scores achievable are 48 and 144 for 4 and $12 h$, respectively. *Significant reductions in scores comparing intervention with $B L, P<0.05$

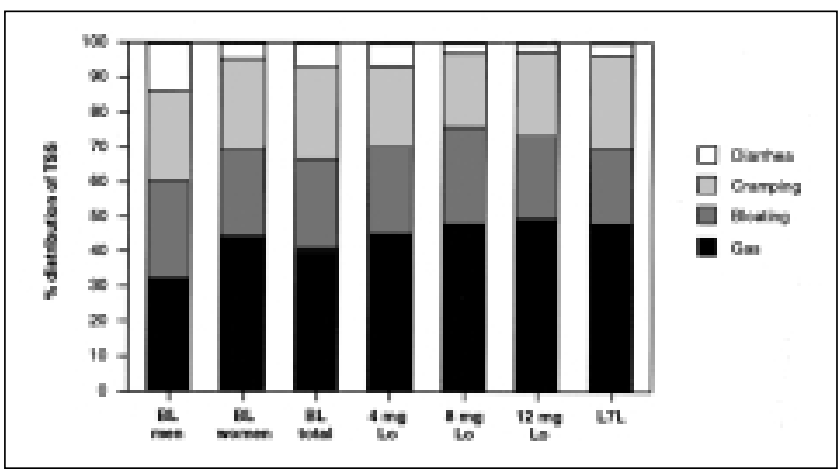

Figure 4) The percentage distribution comprising total symptom score (TSS) for individual symptoms at baseline (BL) for men $(n=7)$, women $(n=11)$, and men and women combined $(n=18)$, as well as for each intervention ( $n=18$ each). Lo Loperamide; L7L Seven lactase tablets

Quantitative differences among treatments in total symptom score, $4 \mathrm{~h} \mathrm{SS}$ and $12 \mathrm{~h} \mathrm{SS}$ with P values are displayed in Table 1. Lactase significantly reduced total SS and $4 \mathrm{~h} \mathrm{SS}$, and showed a trend toward reducing $12 \mathrm{~h} \mathrm{SS}(\mathrm{P}=0.063)$. Lo $8 \mathrm{mg}$ significantly reduced total SS and $4 \mathrm{~h} \mathrm{SS}$, while Lo $4 \mathrm{mg}$ showed a trend for reducing $4 \mathrm{~h} \mathrm{SS}(\mathrm{P}=0.055)$.

Individual symptoms of gas (flatus), bloat, cramps and diarrhea were examined for each intervention. Symptoms
TABLE 2

Symptom scores (SS) (mean \pm SEM) $(n=18)$ for each specified symptom of gas $(G)$, bloat $(B)$, cramps $(C)$ and diarrhea (D) with each intervention (loperamide [Lo] or seven lactase tablets [L7L]), at $4 \mathrm{~h}$ and $12 \mathrm{~h} \mathrm{SS}$

\begin{tabular}{lrllll}
\hline & \multicolumn{1}{c}{ BL } & $\mathbf{4} \mathbf{~} \mathbf{~ g ~ L o}$ & $\mathbf{8} \mathbf{~ m g ~ L o}$ & $\mathbf{1 2} \mathbf{~ m g ~ L o}$ & \multicolumn{1}{c}{ L7L } \\
\hline G 4 h SS & $4.6 \pm 0.9$ & $4.6 \pm 1$ & $4.2 \pm 1$ & $5.4 \pm 1.1$ & $2.7 \pm 0.7^{*}$ \\
B 4 h SS & $4 \pm 0.9$ & $3.1 \pm 0.8$ & $1.8 \pm 0.6$ & $2.2 \pm 0.8$ & $1.6 \pm 0.5$ \\
C 4 h SS & $4.1 \pm 0.8$ & $2.6 \pm 0.9$ & $1.7 \pm 0.5^{*}$ & $3.1 \pm 1$ & $2.2 \pm 1$ \\
D 4 h SS & $3 \pm 0.9$ & $2.1 \pm 0.9$ & $1.3 \pm 0.5^{*}$ & $2.2 \pm 1$ & $1 \pm 0.7^{*}$ \\
G 12 h SS & $6.4 \pm 1.1$ & $5.4 \pm 1.6$ & $3.5 \pm 0.7^{*}$ & $6.2 \pm 1.7$ & $3.6 \pm 1^{*}$ \\
B 12 h SS & $2.6 \pm 1.1$ & $3.1 \pm 0.8$ & $2.9 \pm 1.3$ & $3.4 \pm 1.2$ & $1.2 \pm 0.5$ \\
C 12 h SS & $2.5 \pm 1.2$ & $2.9 \pm 1.2$ & $1.4 \pm 0.7$ & $2.3 \pm 1$ & $1.2 \pm 0.5^{*}$ \\
D 12 h SS & $0.9 \pm 0.4$ & $1.1 \pm 0.6$ & $0.2 \pm 0.1$ & $0.4 \pm 0.7$ & $0.4 \pm 1.1$ \\
\hline
\end{tabular}

The maximum scores for each symptom are 12 and 36 for 4 and $12 h$, respectively. Comparisons are interventions with baseline (BL). ${ }^{*} P<0.05$

were also evaluated to examine any differences in the percentage composition of total symptom score between sexes and among different interventions (Figure 4). In this group, men had fewer gas scores and more diarrhea scores than women. However, gas scores were recorded for all seven men with symptoms and for 10 of 11 women. Five women and four men complained of diarrhea (50\%) during $16 \mathrm{~h}$. The high score in men was due to severe diarrhea in one subject. Therefore, diarrhea was generally not a very prominent complaint and was mild in most. Nevertheless, both of the two higher doses of Lo and L7L reduced diarrhea scores by about half. There was mild compensatory increases in percentage gas scores. The comparisons of individual SS at baseline with those achieved by interventions is shown in Table 2. Lactase significantly reduced $4 \mathrm{~h}$ gas, bloat and diarrhea scores, and $12 \mathrm{~h}$ gas and cramp scores. The $4 \mathrm{~h}$ cramp scores $(\mathrm{P}=0.07)$, and $12 \mathrm{~h}$ bloat $(\mathrm{P}=0.08)$ and diarrhea $(\mathrm{P}=0.052)$ scores showed trends toward decreasing. Eight milligrams of Lo achieved significant reductions in $4 \mathrm{~h}$ scores for cramps and diarrhea and $12 \mathrm{~h}$ scores for gas. The $4 \mathrm{~h}$ bloat $(\mathrm{P}=0.08)$ and $12 \mathrm{~h}$ diarrhea $(\mathrm{P}=0.051)$ scores showed distinguishing trends.

Correlations between $4 \mathrm{~h} \mathrm{SS}$ and AUC were statistically significant for bloat $(R=0.5)$, cramps $(R=0.7)$ and diarrhea $(\mathrm{R}=0.5)$ with $\mathrm{L} 7 \mathrm{~L}$, and for cramps $(\mathrm{R}=0.5)$ with $12 \mathrm{mg} \mathrm{Lo.}$ Trends toward a significant correlation were noted for $\mathrm{L} 7 \mathrm{~L}$ on gas $(\mathrm{R}=0.5, \mathrm{P}=0.052)$, and $8 \mathrm{mg} \mathrm{Lo}(\mathrm{R}=0.4, \mathrm{P}=0.075)$ and $12 \mathrm{mg}$ Lo on diarrhea $(\mathrm{R}=0.5, \mathrm{P}=0.059)$. Statistically significant correlations between $4 \mathrm{~h} \mathrm{SS}$ and OCTT were noted for L7L $(\mathrm{R}=-0.67, \mathrm{P}=0.016)$. Both baseline and $8 \mathrm{mg}$ Lo showed trends toward statistical significance, with inverse correlations between $4 \mathrm{~h} \mathrm{SS}$ and OCTT (baseline $=-0.39, \mathrm{P}=0.1$ and $8 \mathrm{mg} \mathrm{R}=-0.44, \mathrm{P}=0.07$ ) (Table 3 ). The $\mathrm{SS}$ changes achieved with L7L and Lo doses ( 4 to $12 \mathrm{mg}$ ) were not significantly different. The correlation between gas and bloat scores at baseline, and with each of the interventions, were examined. The only correlation that approached significance was that with $\mathrm{L} 7 \mathrm{~L}$, with a correlation factor of $\mathrm{R}=0.40$ $(\mathrm{P}=0.056)$. 
TABLE 3

Spearman correlation coefficients with $P$ values for trends between individual symptom scores at $4 \mathrm{~h}$, and area under curve (AUC) or oral cecal transit time (OCTT)

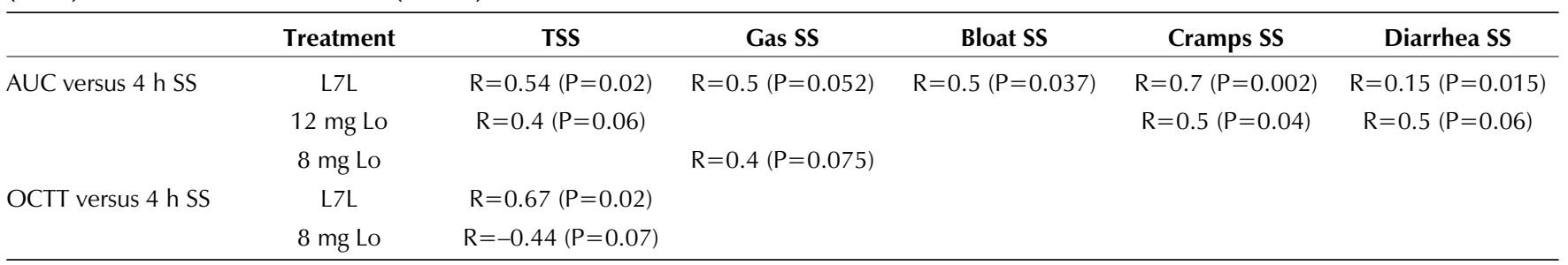

Lo Loperamide; L7L Seven lactase tablets; SS Symptom score; TSS Total symptom score

Late symptoms ( $24 \mathrm{~h}$ ) of constipation were noted by two women - one taking $8 \mathrm{mg}$ Lo and another taking 8 and $12 \mathrm{mg}$ Lo. One other woman noted delayed cramps with 8 and $12 \mathrm{mg}$ Lo, and one woman complained of late cramps and delayed diarrhea with $4 \mathrm{mg}$ Lo. One additional woman complained of burps with all studies using the $25 \mathrm{~g}$ lactose.

\section{DISCUSSION}

Lo is an opioid-like agent with gastrointestinal and minimal central nervous system effects. Although in lower doses it has effects on intestinal electrolyte transport and prostaglandin-induced secretion, in larger doses intestinal transit is prolonged (20) via an agonist effect on mu-opioid receptors. The recommended total daily dose is 12 to $16 \mathrm{mg}$, but higher single doses have been used in studies without important ill effects (21).

The rationale for using delayed intestinal transit to affect symptoms of carbohydrate intolerance is derived from a number of sources. Large doses of Lo have been shown to aid patients with postvagotomy diarrhea (21). As well, it has been shown that the quantity of undigested carbohydrate delivered across the ileocecal valve influences hydrogen production per unit time (9). For other substances, delaying intestinal transit may increase mucosal substrate contact time and lead to modestly improved absorption (22). A similar effect may occur with lactose in subjects with partial lactase insufficiency. Finally, we have previously reported symptomatic improvement of lactose intolerance using Lo in a group of men challenged with $50 \mathrm{~g}$ of lactose (13).

An accepted therapy of lactose intolerance is the use of self-regulated doses of manufactured beta-galactosidase. Although these external enzymes are good, they do not work uniformly with all subjects and have variable effects on large test doses of lactose (14). The optimal effective dose of enzymes used in this study was six tablets before challenge (personal communication). Seven tablets were, therefore, considered to be a good dose as a positive control to compare with the effects of Lo. Indeed, in the majority of symptomatic subjects, SS improved and AUC values were reduced after a lactose challenge. Furthermore, therapy with lactase demonstrated expected significant correlative relationships between AUC and SS (11), and between SS and OCTT (10). The latter relationship in this case is likely a reflection of reduced osmotic influence of digested lactose on OCTT.
Nevertheless, it serves as a model to demonstrate the balanced effects of two variables - quantity of undigested lactose and manipulation of OCTT on symptoms. It reinforces the concept that symptoms may be altered either by reducing quantity of lactose or by artificially prolonged OCTT.

The present study found a statistically significant improvement in SS with $8 \mathrm{mg}$ Lo overall. The effect was short term and mainly influenced the initial $4 \mathrm{~h}$ following lactose challenge. This was not very different from symptomatic improvement with lactase. Examination of the influence on individual symptoms showed that, while lactase significantly affected gas, bloat and diarrhea, the main contribution of Lo was reduction in cramps and diarrhea. Both the $8 \mathrm{mg}$ Lo and lactase halved diarrhea scores and resulted in a mild compensatory increase in gas scores. The relationship between gas and bloat, despite showing a roughly two to one ratio, did not correlate. These data support the contention that bloat is a feature of a hypersensitive bowel (23).

The ideal results with Lo would have been a statistically significant influence of the $12 \mathrm{mg}$ Lo dose on AUC, prolonged OCTT and decreased symptoms. These did not occur, raising the possibility of a chance occurrence that $8 \mathrm{mg}$ was effective. However, we do not think that this is likely. First, expected trends of dose response in median AUC and mean OCTT were observed. Second, statistically significant trends ( $\mathrm{P}$ 0.1) were noted with $4 \mathrm{mg}$ Lo and $8 \mathrm{mg}$ Lo. Third, in a previous study, $8 \mathrm{mg}$ Lo significantly reduced symptoms despite failure to reduce AUC significantly (18). Fourth, although the AUC with $12 \mathrm{mg}$ Lo was slightly less than AUC with $8 \mathrm{mg} \mathrm{Lo}$, variation was greater with the former and, in fact, the mean AUC with $12 \mathrm{mg}$ Lo was higher than that with $8 \mathrm{mg}$ Lo (data not shown). Because we confirmed that the expected correlations of symptoms with hydrogen production (24), AUC (11) or OCTT (10) occur with lactase, the higher AUC with $12 \mathrm{mg}$ Lo may partly explain why symptoms did not improve. Furthermore, we did not detect any significant differences in OCTT between men and women, negating any possible influence of the menstrual cycle (25-28). We, therefore, have to consider that the greater individual variability with the $12 \mathrm{mg}$ Lo dose may account for the lack of the expected outcome. Despite our calculations of the number of required subjects, the sensitivity of the present study may have been too low. Alternatively, it is 
possible that different doses of lactose challenge require different optimal doses of Lo.

It was outlined above that an alteration in the way in which lactose intolerance is managed may be rational because colonic bacterial adaptation may be beneficial for prophylaxis against a number of diseases $(7,8)$. Colonic adaptation leads to altered microbial flora or floral metabolism. There is some evidence, albeit requiring further confirmation, that in the face of lactase insufficiency, bifido bacteria become more prominent (29). Hertzler et al (8) suggested that one way to alter management is through daily consumption of dairy products, which after a few weeks would lead to adaptation. Two studies concluded that lactose intolerant subjects can consume dairy products (particularly milk) if it contains less than $8 \mathrm{oz}$ or equivalent amounts of lactose $(30,31)$. Consequently, continued consumption could lead to adaptation.

Alternatively, there are subjects who may wish to use medication with larger doses of lactose in the short term to achieve adaptation. It is in this group that Lo may be of some value. However, we cannot recommend Lo in the doses used in this study (four tablets before dairy consumption) because of the unknown effect of cumulative doses. In the present study, although only four $(21.5 \%)$ complained of delayed or prolonged constipation and cramps, the effect of multiple dosing on a regular basis is unknown. The use of combination of suboptimal doses of lactase and lower, more conventional doses of Lo may be useful. However, additional studies are needed to establish this point.

Lo may be of benefit in intolerance to other carbohydrates where no enzyme replacement is available, including

\section{REFERENCES}

1. Scrimshaw NS, Murray EB. The acceptability of milk and milk products in populations with a high prevalence of lactose intolerance. Am J Clin Nutr 1988;48:1086-159.

2. Newcomer AD, Hodgson SF, McGill DB, Thomas PJ. Lactase deficiency: Prevalence inosteoporosis. Ann Intern Med 1978;89:218-20.

3. Lupton JR. Dairy products and colon cancer: mechanisms of the protective effect. Am J Clin Nutr 1997;66:1065-6.

4. Marteau P, Rambaud JC. Potential of using lactic acid bacteria for therapy and immunomodulation in man. FEMS Microbiol Rev 1993;12:207-20.

5. Liao W, Cui XS, Jin XY, Floren CH. Lactulose - a potential drug for the treatment of inflammatory bowel disease. Med Hypoth 1994:43:234-8

6. Szilagyi A. Altered colonic environment, a possible predisposition to colorectal cancer and colonic inflammatory bowel disease: Rationale of dietary manipulation with emphasis on disaccharides. Can J Gastroenterol 1998;12:133-46.

7. Hertzler S, Savaiano DA. Colonic adaptation to daily lactose feeding in lactose maldigesters reduces lactose intolerance. Am J Clin Nutr 1996;64:232-6.

8. Hertzler SR, Savaiano DA, Levitt MD. Fecal hydrogen production and consumption measurements. Response to daily lactose ingestion by lactose maldigesters. Dig Dis Sci 1997;42:348-53.

9. Read NW, Al-Janabi MN, Bates TE, et al. Interpretation of the breath hydrogen profile obtained after ingesting a solid meal containing unabsorbable carbohydrate. Gut 1985;26:834-42.

10. Ladas S, Papanikos J, Arapakis G. Lactose malabsorption in Greek adults: correlation of small bowel transit time with the severity of lactose intolerance. Gut 1982;23:968-73.

11. Szilagyi A, Salomon R, Martin M, Fokeeff K, Seidman E. Lactose fructose, sorbitol and possibly sucrase insufficiency. However, the magnitude of the problem of fructose sorbitol intolerance is not as well defined as with lactose. One study suggested that the likelihood of intolerance to these sugars is independent of ethnicity and is also more likely with lactose intolerance (32). Furthermore, it may not be possible to adapt colonic bacteria to repeated doses of fructose (33). Therefore, it may be worthwhile to evaluate further the role of Lo with intolerance to these sugars.

\section{SUMMARY AND CONCLUSIONS}

The present study confirms previous observations that Lo in higher than currently recommended doses can improve symptoms induced by a lactose challenge in lactase nonpersistent subjects. However, different optimal doses of Lo may be required with different doses of ingested lactose. Under the present conditions, the results do not support the regular use of Lo as a temporary aid in reducing symptoms of lactose intolerance while colonic adaptation occurs. The reasons for this are that it is not economical and more importantly that cumulative effects of larger doses of Lo are not clearly defined. The possibility exists that combinations of more conventional doses of Lo with submaximal doses of lactase may reduce symptoms with larger volumes of dairy products (400 $\mathrm{mL}$ or more milk) and allow colonic adaptation. However additional studies would have to verify this.

ACKNOWLEDGEMENTS: We thank Ms Alison Szilagyi for help with calculations and Ms Florence Lurie for typing the manuscript. handling by women with lactose malabsorption is improved during pregnancy. Clin Invest Med 1996;19:416-26.

12. Szilagy A, Salomon R, Smith BE, Fokeef K, Martin M, Seidman E. Determinants of prolonged oral cecal transit time (OCTT) during third trimester pregnancy. Clin Invest Med 1996;19:20-7.

13. Szilagyi A, Salomon R, Seidman E. Influence of loperamide on lactose handling and oral caecal transit time. Aliment Pharmacol Ther 1996;10:765-70.

14. Lin MY, Dipalma J, Martini MC, Gross CJ, Harlander SK, Savaiano DA. Comparative effects of exogenous lactase ( -galactosidase) preparations on in vivo lactose digestion. Dig Dis Sci 1993;38:2022-7.

15. Metz G, Gassull MA, Leeds AR, Blendis LM, Jenkins DJ. A simple method of measuring breath hydrogen in carbohydrate malabsorption by end-expiratory sampling. Clin Sci Mol Med 1976;50:237-40.

16. Van der Klei-Van Moorsel JM, Douwes AC, Van Oeveren JC. New principle for estimation of hydrogen in expired air. Eur J Pediatr 1984;141:221-4.

17. Strocchi A, Corazza E, Ellis CJ, Gasbarrini G, Levitt MD. Detection of malabsorption of low doses of carbohydrate: accuracy of various breath $\mathrm{H}_{2}$ criteria. Gastroenterology 1993;105:1404-10.

18. Rumessen JJ, Hamberg Ok, Gudmand-Hoyers E. Interval sampling of end-expiratory hydrogen $\left(\mathrm{H}_{2}\right)$ concentrations to quantify carbohydrate malabsorption by means of lactulose standards. Gut 1990;31:37-42.

19. Barr RG, Watkins JB, Perman JA. Mucosal function and breath hydrogen excretion: comparative studies in the clinical evaluation of children with non-specific abdominal complaints. Pediatrics 1981;68:526-32. 
20. Awouters F, Megens A, Verlinden M, Schuurkes J, Niemegeers C, Janssen PAJ. Loperamide: survey of studies on mechanism of its antidiarrheal activity. Dig Dis Sci 1993;38:977-95.

21. O'Brien JD, Thompson DG, Mcintyre A, Burnham WR, Walker E. Effect of codeine and loperamide on upper intestinal transit and absorption in normal subjects and patients with post vagotomy diarrhea. Gut 1988;29:312-8.

22. Eisenbraun J, Ehrlein HK. Effects of somatostatin on luminal transit and absorption of nutrients in the proximal gut of minipigs. Dig Dis Sci 1996;41:894-901.

23. Levitt MD, Furne J, Olsson S. The relation of passage of gas and abdominal bloating to colonic gas production. Ann Intern Med 1996;124:422-4.

24. Kajs TM, Fitzgerald JA, Buckner RY, et al. Influence of a methanogenic flora on the breath $\mathrm{H}_{2}$ and symptom response to ingestion of sorbitol or oat fiber. Am J Gastroenterol 1997;92:89-94.

25. Wald A, Van Thiel OH, Hoechstetter L, et al. Gastrointestinal transit: the effect of the menstrual cycle. Gastroenterology 1981;80:1497-500.

26. Whitehead WE, Cheskin LJ, Heller BR, et al. Evidence for exacerbation of irritable bowel syndrome during menses. Gastroenterology 1990;98:1485-9.

27. Turnbull GK, Thompson DG, Day S, Martin J, Walker E, Lennard-Jones JE. Relationships between symptoms menstrual cycle and orocaecal transit in normal and constipated women. Gut 1989;30:30-4

28. Kamm MA, Farthing MJG, Lennard-Jones JE. Bowel function and transit rate during the menstrual cycle. Gut 1989;30:605-8.

29. Hill MJ. Bacterial adaptation to lactase deficiency. In: Delmont J, ed. Milk Intolerances and Rejection. New York: Krager, 1983:22-6.

30. Vesa TH, Korpela RA, Sahi T. Tolerance to small amounts of lactose in lactose maldigesters. Am J Clin Nutr 1996;64:197-201.

31. Suarez F, Savaiano DA, Levitt MD. A comparison of symptoms after the consumption of milk or lactose-hydrolysed milk by people with self-reported severe lactose intolerance. N Engl J Med 1995;333:1-4.

32. Mishkin D, Sablauskas L, Yalovsky M, Mishkin S. Fructose and sorbitol malabsorption in ambulatory patients with functional dyspepsia - comparison with lactose maldigestion/malabsorption. Dig Dis Sci 1997;12:2591-8.

33. Briet F, Achour L, Flourie B, et al. Symptomatic response to varying levels of fructo-oligo-saccharides consumed occasionally or regularly. Eur J Clin Nutr 1995;49:501-7. 


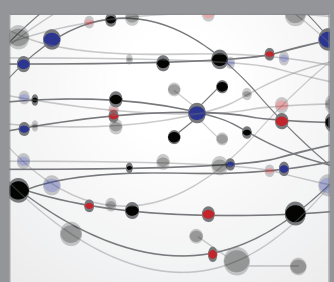

The Scientific World Journal
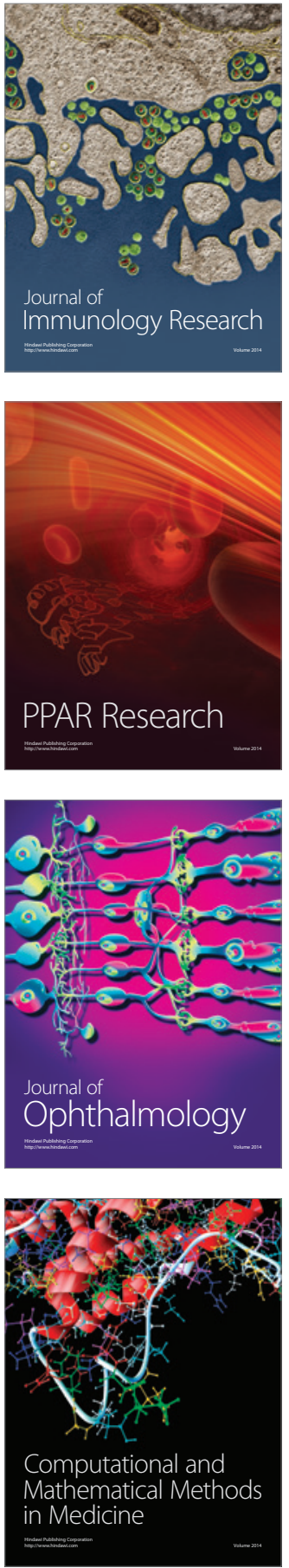

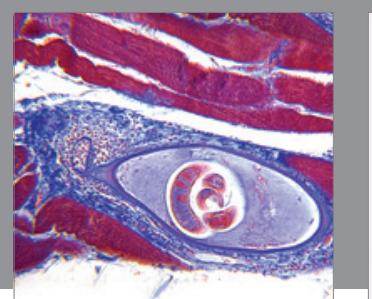

Gastroenterology Research and Practice

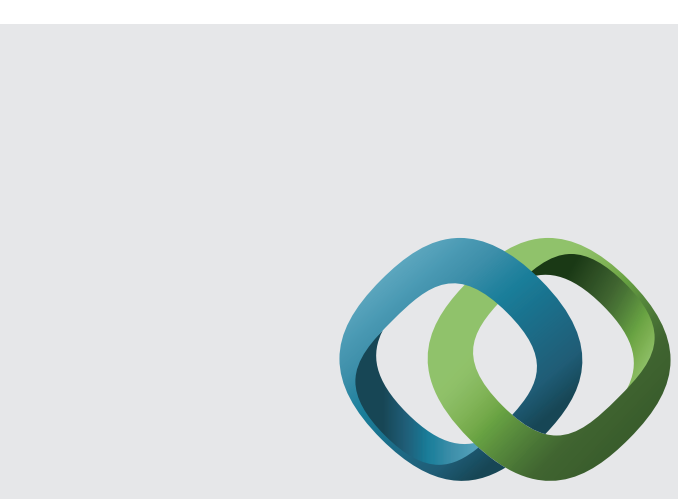

\section{Hindawi}

Submit your manuscripts at

http://www.hindawi.com
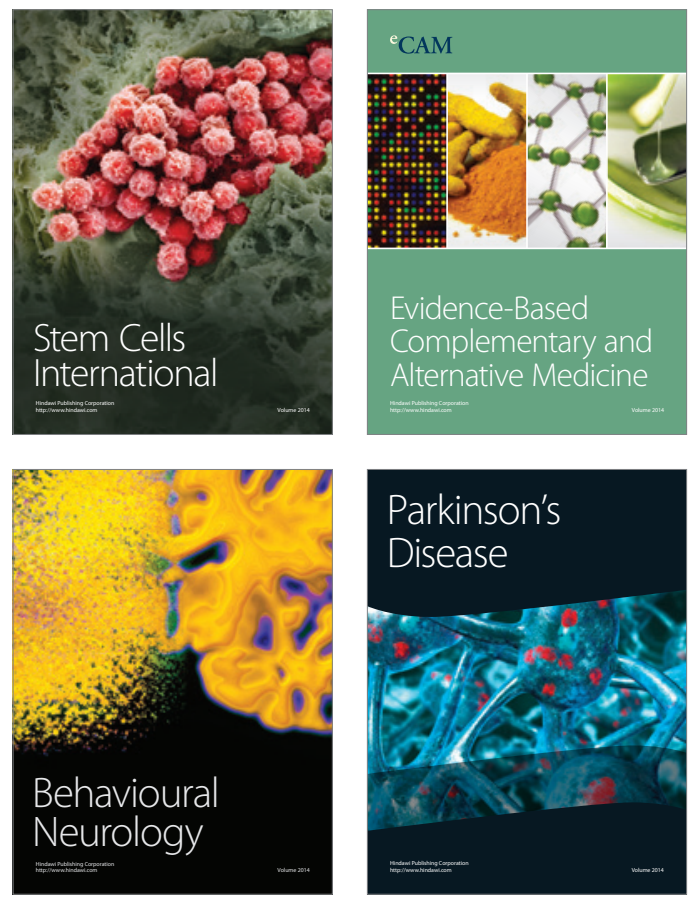
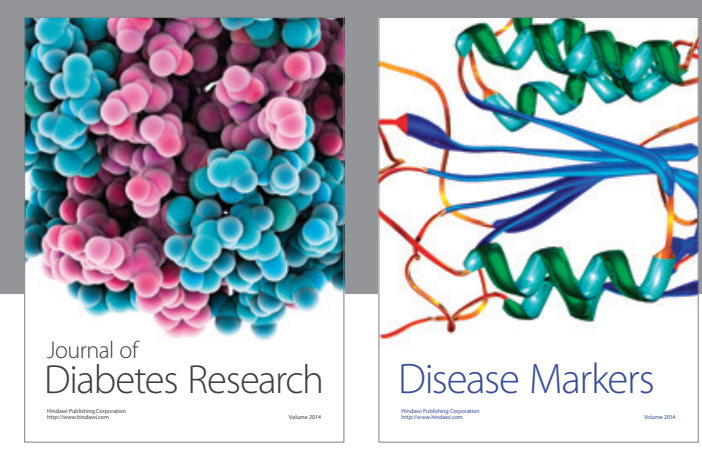

Disease Markers
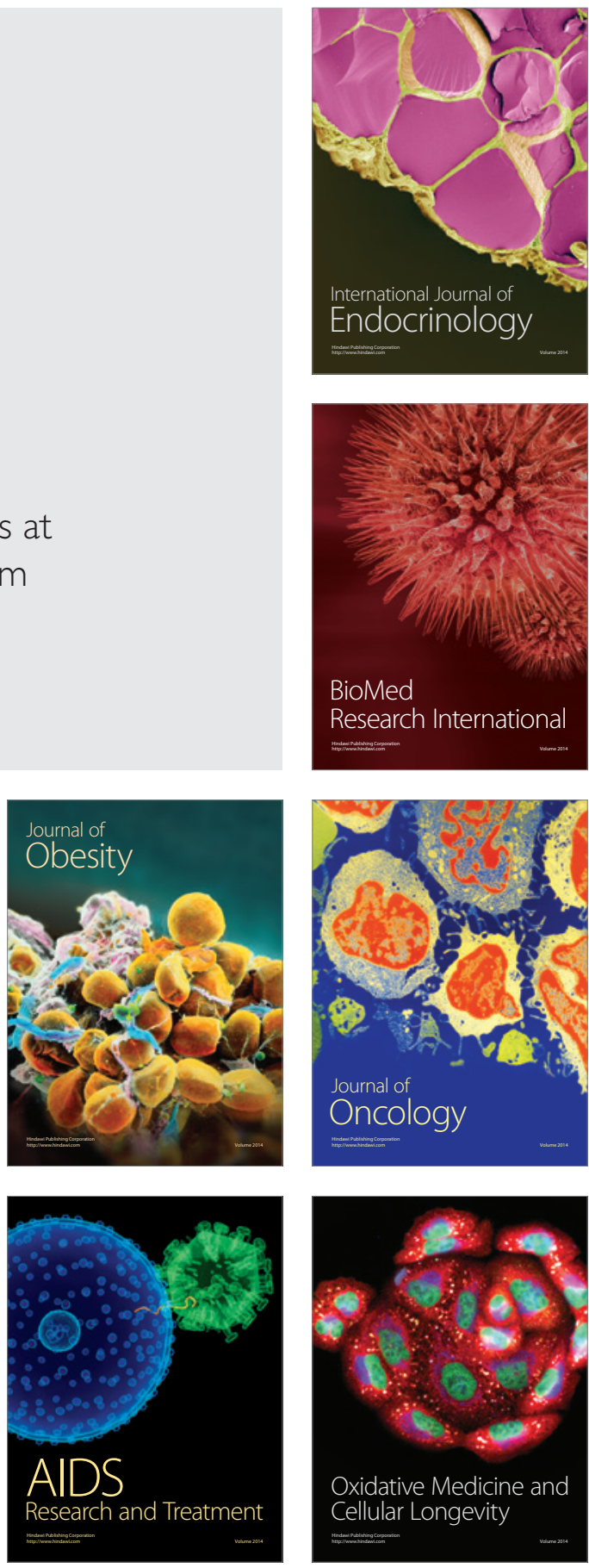